\title{
Role of Enteroscopic Techniques in Malignant Complications of Celiac Disease
}

\author{
Carolina Tomba, Federica Branchi, Dario Conte, Maria Teresa Bardella, Luca Elli* \\ Center for the Prevention and Diagnosis of Celiac Disease and Gastroenterology Unit II - Fondazione IRCCS Ca’ Granda-Ospedale \\ Maggiore Policlinico and Università degli Studi di Milano - via F.Sforza, Milan, Italy \\ *Corresponding author: dottorlucaelli@gmail.com
}

Received December 25, 2013; Revised December 30, 2013; Accepted January 02, 2014

Keywords: celiac disease, small bowel malignancy, risk factors, capsule endoscopy, double-balloon enteroscopy

Cite This Article: Carolina Tomba, Federica Branchi, Dario Conte, Maria Teresa Bardella, and Luca Elli, "Role of Enteroscopic Techniques in Malignant Complications of Celiac Disease." International Journal of Celiac Disease 2, no. 1 (2014): 1-3. doi: 10.12691/ijcd-2-1-1.

Celiac disease (CD) is the most common autoimmune enteropathy in western countries with an estimated prevalence of 1:100 subjects. [1,2,3] Ingestion of gluten is the primum movens, which triggers autoimmune response in genetically predisposed patients, carrying the HLA type II DQ2 and/or DQ8 haplotypes. Intestinal damage is characterized by intraepithelial lymphocytosis, crypt hyperplasia and villous atrophy. In most patients, strict gluten withdrawal usually leads to symptomatic remission and small bowel healing $[4,5,6]$.

Notwithstanding the proven efficacy of the sole dietary treatment, some problems can occur throughout the course of the disease. Alimentary and consequent lifestyle restrictions could influence the quality of life even if symptoms show a satisfying response to the treatment. Autoimmune disorders and other types of comorbidities represent frequent findings in these patients. [7,8] Moreover, in a small minority of CD patients, absence of response to gluten withdrawal can occur with the onset of a refractory state. Refractory CD (RCD) can be diagnosed in patients presenting persistent or novel malabsorption symptoms and intestinal atrophy during gluten free diet (GFD). RCD is classified into type I and type II; the first is usually a temporary defect of response to GFD, reverting after glucocorticoid therapy; the second is a clinically severe syndrome, defined by the presence of phenotypic changes (TCR $\gamma$ monoclonal rearrangement) of intraepithelial lymphocytes and present relevant prognostic implications. Up to $70 \%$ of RCD II patients develop ulcerative lesions involving jejunum and ileum with clinical deterioration due to the associated protidodispersion. [9] Moreover, RCD II is usually considered a preneoplastic condition with $50 \%$ of cases developing an enteropathy associated T cell lymphoma (EATL). [10,11] Unfortunately, EATL diagnosis is often performed at a late stage, frequently during an urgent surgical intervention due to intestinal perforation, bleeding or occlusion. Consequently, the survival rate is very poor, close to zero after 5 years. Recent novelties in RCD II and EATL treatment are represented by the introduction of high-dose chemotherapy, autologous stem cell transplantation or the use of biologic drugs targeting the key factors involved in their pathogenesis, mainly IL15 pathway. However, the main limitation in most of the cases is the diagnostic delay, limiting prognosis and access to therapy [12].

Also small bowel adenocarcinoma has been reported to be more frequent in CD patients with a 10 fold increased relative risk as showed by recent data. [13] Given its rarity in the general population, data about this association are limited to case reports and small case series [14].

Poor prognosis and site-related diagnostic difficulties make intestinal malignant CD complications a challenging issue. Firstly, a high level of clinical suspicion is required. Secondly, direct small bowel exploration has been impossible since the introduction of the enteroscopic techniques, mainly capsule and device-assisted enteroscopy which allow the complete visualization and the histologic sampling of small bowel, respectively. Thirdly, hidden CD cases are not associated with an increased risk of intestinal lymphoma [15] and enteroscopies are expensive, invasive (device-assisted enteroscopy) and potentially burdened by adverse events. For these reasons a screening program for early diagnosis of CD and/or a surveillance plan for detection of complications in the CD population cannot be supported. In this setting, selection of patients deserving a strict follow up is a relevant topic.

The profile of at risk CD patients needing small bowel endoscopy could be sketched on the basis of the following factors: [16]

1. age over 50 years and male gender, being the peak of incidence of both intestinal lymphoma and adenocarcinoma in the sixth decade with a slight predominance in men [17]

2. presence of unexplained gastrointestinal symptoms, fever, weight loss or suspected mid-gut bleeding

3. long-standing poor dietary compliance $[18,19]$.

Although these factors remain the only available, it is noteworthy that evidence is poor and literature data are conflicting [12,13,18,20,21,22].

As far as prognostic prediction is concerned, mucosal healing has been considered a key factor. In fact, 
persistence of atrophic lesions in patients with a good dietary adherence has been associated with a worse prognosis. [23] However, when estimating risk, the low rate of histological normalization observed in the adult CD population (as low as $25 \%$ in a study by our group) [24] should be taken into consideration. In general, the permanence of atrophy during GFD should prompt questions about dietary adherence, presence of concomitant/alternative atrophic enteropathy or of a true refractory state. Unfortunately, population studies evaluating this item do not provide these data.

Finally, knowledge about premalignant conditions is very poor. EATL has been documented also in the presence of non atrophic lesions (grade I or II according to Marsh-Oberhuber classification) [25] in the adjacent mucosa. [26] No dysplastic changes have been observed in the flat mucosa surrounding small bowel adenocarcinoma in CD cases (as observed in Crohn's disease) but few cases leaded to the hypothesis of a possible adenoma-carcinoma sequence [14].
In the attempt to detect small bowel lesions, which take origin from the mucosal layer, at an early stage, enteroscopic techniques emerge as an optimal choice. Capsule endoscopy (CE) has been proposed as an useful tool for the surveillance of malignant CD complications and for investigating persistent or novel symptoms despite an ongoing GFD. [27,28] New generation capsules, with high resolution and magnification power, allow the detection of even minimal mucosal abnormalities. Capsule endoscopy is the only non invasive approach which enables the direct visualization of the small bowel in its full extent. However, despite its unique properties, some limitations should be noticed. Most literature deals with CE use for exclusion of complications (ulcerative jejunoileitis and EATL) in the setting of a known RCD. Studies involving "non responsive" CD patients, with or without RCD, showed a diagnostic yield of CE for small bowel complications ranging from 5\% [29] to 60\%[30] and mainly presented a retrospective design (Table 1).

Table 1. Main studies evaluating the use of capsule endoscopy in complicated celiac disease

\begin{tabular}{cccc} 
& Table 1. Main studies evaluating the use of capsule endoscopy in complicated celiac disease & Diagnosis \\
\hline Culliford 2005[30] & Inclusion criteria & Diagnostic yield & Ulcers, adenocarcinoma, stenosis, polyp, submucosal mass \\
Daum 2007[31] & Symptoms, Surveillance, Anemia & $60 \%$ & $7 \%$ \\
Maiden 2009[32] & RCD & $11 \%$ & EATL \\
Atlas 2011[29] & Non responsive CD & $5 \%$ & Ulcers \\
Van Weyenberg 2012[33] & Non responsive CD & $10 \%$ & UJ, adenocarcinoma \\
Collin 2012[34] & Non responsive CD & $47 \%$ & UJ, EATL \\
Barret 2012[35] & NCD & $6 \%$ & Ulcers, stenosis \\
Kurien 2013[36] & Ulcers & EATL \\
\hline
\end{tabular}

$\mathrm{CD}=$ celiac diasease; EATL= enteropathy associated T cell lymphoma; UJ=ulcerative jejunoileitis; RCD=refractory celiac disease.

Most frequent findings in CD include scalloping, loss of folds, mucosal nodularity. Features of mucosal atrophy are also detectable in uncomplicated CD cases, [29] but they usually present a more extensive involvement of the small bowel in RCD II patients. [35] Such cases are characterized by prolonged small bowel transit and, frequently, ulcers. Ulcerative lesions lack of specificity and are commonly shared by inflammatory, infectious and NSAIDs-related enteropathies; up to $10 \%$ of uncomplicated CD cases and 14\% of non-CD subjects can show erosive mucosal alterations. [37] However, in RCD II patients they result larger, numerous and usually localized in the distal tract of the small bowel. [35] Endoscopic appearance of intestinal lymphoma comprehends nodules, plaques, ulcers and, rarely, masses but agreement in defining these findings, their predictive value and clinical relevance is still poor. When endoscopic images at CE remain doubtful, device-assisted enteroscopy allows a definite diagnosis through bioptic sampling and histological evaluation. In one study evaluating the usefulness of double-balloon enteroscopy in RCD patients, diagnostic yield for EATL and ulcerative jejunoileitis was limited to the subgroup presenting major endoscopic lesions (ulcers and stenosis) [26].

In conclusion, enteroscopic techniques represent the unique tools to obtain direct visualization of the small bowel and mucosal sampling. The possibility to detect intestinal lesions at an early stage could improve the prognosis of complicated CD patients at risk to develop malignancy. Since they are expensive and invasive, an appropriate selection of patients, through a better knowledge of their profile possibly involving novel molecular markers, is mandatory [38].

\section{References}

[1] Volta U, Bellentani S, Bianchi FB, Brandi G, De Franceschi L, Miglioli L, Granito A, Balli F, Tiribelli C. High prevalence of celiac disease in Italian general population. Dig Dis Sci 2001 Jul; 46(7): 1500-1505.

[2] Elli L, Bardella MT. Motility disorders in patients with celiac disease. Scand J Gastroenterol 2005 Jul; 40(7): 743-749.

[3] Rimarova K. Celiac Diseases - Global Demographic Context and Slovakia. International Journal of Celiac Disease 2013; 1(1): 1718.

[4] Elli L, Bergamini CM, Bardella MT, Schuppan D. Transglutaminases in inflammation and fibrosis of the gastrointestinal tract and the liver. Dig Liver Dis 2009 Aug; 41(8): 541-550.

[5] Schuppan D, Junker Y, Barisani D. Celiac disease: from pathogenesis to novel therapies. Gastroenterology 2009 Dec; 137(6): 1912-1933.

[6] Marsh MN. Another Milestone Passed. International Journal of Celiac Disease 2013; 1(1): 1-2.

[7] Elli L, Bonura A, Garavaglia D, Rulli E, Floriani I, Tagliabue G, Contiero P, Bardella MT. Immunological comorbity in coeliac disease: associations, risk factors and clinical implications. J Clin Immunol 2012 Oct; 32(5): 984-990.

[8] Bardella MT, Elli L, Velio P, Fredella C, Prampolini L, Cesana B. Silent celiac disease is frequent in the siblings of newly diagnosed celiac patients. Digestion 2007; 75(4): 182-187.

[9] Cellier C, Delabesse E, Helmer C, Patey N, Matuchansky C, Jabri B, Macintyre E, Cerf-Bensussan N, Brousse N. Refractory sprue, coeliac disease, and enteropathy-associated T-cell lymphoma. French Coeliac Disease Study Group. Lancet 2000 Jul 15; 356(9225): 203-208. 
[10] Cil T, Altintas A, Isikdogan A, Pasa S, Bayan K, Batun S, Buyukbayram H. Screening for Celiac disease in Hodgkin and non-Hodgkin lymphoma patients. Turk J Gastroenterol 2009 Jun; 20(2): 87-92.

[11] Daum S, Cellier C, Mulder CJ. Refractory coeliac disease. Best Pract Res Clin Gastroenterol 2005 Jun; 19(3): 413-424.

[12] Green PH, Fleischauer AT, Bhagat G, Goyal R, Jabri B, Neugut AI. Risk of malignancy in patients with celiac disease. Am J Med 2003 Aug 15; 115(3): 191-195.

[13] Askling J, Linet M, Gridley G, Halstensen TS, Ekstrom K, Ekbom A. Cancer incidence in a population-based cohort of individuals hospitalized with celiac disease or dermatitis herpetiformis. Gastroenterology 2002 Nov; 123(5): 1428-1435.

[14] Rampertab SD, Forde KA, Green PH. Small bowel neoplasia in coeliac disease. Gut 2003 Aug; 52(8): 1211-1214.

[15] Elli L, Contiero P, Tagliabue G, Tomba C, Bardella MT. Risk of intestinal lymphoma in undiagnosed coeliac disease: Results from a registered population with different coeliac disease prevalence. Dig Liver Dis 2012 Sep; 44(9): 743-747.

[16] Green PH, Rubin M. Capsule endoscopy in celiac disease: diagnosis and management. Gastrointest Endosc Clin N Am 2006 Apr; 16(2): 307-316.

[17] Freeman HJ. Adult celiac disease in the elderly. World J Gastroenterol 2008 Dec 7; 14(45): 6911-6914.

[18] Holmes GK, Prior P, Lane MR, Pope D, Allan RN. Malignancy in coeliac disease--effect of a gluten free diet. Gut 1989 Mar; 30(3): 333-338.

[19] Elli L, Discepolo V, Bardella MT, Guandalini S. Does Gluten Intake Influence the Development of Celiac Disease-associated Complications? J Clin Gastroenterol 2013 Jan; 48(1): 13-20.

[20] Catassi C, Fabiani E, Corrao G, Barbato M, De Renzo A, Carella AM, Gabrielli A, Leoni P, Carroccio A, Baldassarre M, Bertolani P, Caramaschi P, Sozzi M, Guariso G, Volta U, Corazza GR. Risk of non-Hodgkin lymphoma in celiac disease. Jama 2002 Mar 20; 287(11): 1413-1419.

[21] Olen O, Askling J, Ludvigsson JF, Hildebrand H, Ekbom A, Smedby KE. Coeliac disease characteristics, compliance to a gluten free diet and risk of lymphoma by subtype. Dig Liver Dis 2011 Nov; 43(11): 862-868.

[22] Howdle PD, Jalal PK, Holmes GK, Houlston RS. Primary smallbowel malignancy in the UK and its association with coeliac disease. Qjm 2003 May; 96(5): 345-353.

[23] Kaukinen K, Peraaho M, Lindfors K, Partanen J, Woolley N, Pikkarainen P, Karvonen AL, Laasanen T, Sievanen H, Maki M, Collin P. Persistent small bowel mucosal villous atrophy without symptoms in coeliac disease. Aliment Pharmacol Ther 2007 May 15; 25(10): 1237-1245.

[24] Bardella MT, Velio P, Cesana BM, Prampolini L, Casella G, Di Bella C, Lanzini A, Gambarotti M, Bassotti G, Villanacci V. Coeliac disease: a histological follow-up study. Histopathology 2007 Mar; 50(4): 465-471.
[25] Oberhuber G, Granditsch G, Vogelsang H. The histopathology of coeliac disease: time for a standardized report scheme for pathologists. Eur J Gastroenterol Hepatol 1999 Oct; 11(10): 11851194.

[26] Hadithi M, Al-toma A, Oudejans J, van Bodegraven AA, Mulder $\mathrm{CJ}$, Jacobs $\mathrm{M}$. The value of double-balloon enteroscopy in patients with refractory celiac disease. Am J Gastroenterol 2007 May; 102(5): 987-996.

[27] Cellier C, Green PH, Collin P, Murray J. ICCE consensus for celiac disease. Endoscopy 2005 Oct; 37(10): 1055-1059.

[28] Sidhu R, Sanders DS, Morris AJ, McAlindon ME. Guidelines on small bowel enteroscopy and capsule endoscopy in adults. Gut 2008 Jan; 57(1): 125-136.

[29] Atlas DS, Rubio-Tapia A, Van Dyke CT, Lahr BD, Murray JA Capsule endoscopy in nonresponsive celiac disease. Gastrointest Endosc 2011 Dec; 74(6): 1315-1322.

[30] Culliford A, Daly J, Diamond B, Rubin M, Green PH. The value of wireless capsule endoscopy in patients with complicated celiac disease. Gastrointest Endosc 2005 Jul; 62(1): 55-61.

[31] Daum S, Wahnschaffe U, Glasenapp R, Borchert M, Ullrich R, Zeitz M, Faiss S. Capsule endoscopy in refractory celiac disease. Endoscopy 2007 May; 39(5): 455-458.

[32] Maiden L, Elliott T, McLaughlin SD, Ciclitira P. A blinded pilot comparison of capsule endoscopy and small bowel histology in unresponsive celiac disease. Dig Dis Sci 2009 Jun; 54(6): 12801283.

[33] Van Weyenberg SJ, Smits F, Jacobs MA, Van Turenhout ST, Mulder CJ. Video Capsule Endoscopy in Patients With Nonresponsive Celiac Disease. J Clin Gastroenterol 2012 Nov 15.

[34] Collin P, Rondonotti E, Lundin KE, Spada C, Keuchel M, Kaukinen K, R DEF, Jacobs MA, Villa F, Mulder CJ. Video capsule endoscopy in celiac disease: current clinical practice. J Dig Dis 2012 Feb; 13(2): 94-99.

[35] Barret M, Malamut G, Rahmi G, Samaha E, Edery J, Verkarre V, Macintyre E, Lenain E, Chatellier G, Cerf-Bensussan N, Cellier C. Diagnostic yield of capsule endoscopy in refractory celiac disease. Am J Gastroenterol 2012 Oct; 107(10): 1546-1553.

[36] Kurien M, Evans KE, Aziz I, Sidhu R, Drew K, Rogers TL, McAlindon ME, Sanders DS. Capsule endoscopy in adult celiac disease: a potential role in equivocal cases of celiac disease? Gastrointest Endosc 2012 Feb; 77(2): 227-232.

[37] Goldstein JL, Eisen GM, Lewis B, Gralnek IM, Zlotnick S, Fort JG. Video capsule endoscopy to prospectively assess small bowel injury with celecoxib, naproxen plus omeprazole, and placebo. Clin Gastroenterol Hepatol 2005 Feb; 3(2): 133-141.

[38] Vaira V, Roncoroni L, Barisani D, Gaudioso G, Bosari S, Bulfamante G, Doneda L, Conte D, Tomba C, Bardella MT, Ferrero S, Locatelli M, Elli L. microRNA profiles in coeliac patients distinguish different clinical phenotypes and are modulated by gliadin peptides in primary duodenal fibroblasts. Clin Sci (Lond) 2014 Mar 1; 126(6): 417-423. 